\title{
Pathological roles of platelets in inflammatory diseases: The emerging targets for new drug development
}

\author{
Surasak Wichaiyo ${ }^{1,2 *}$, Arnatchai Maiuthed ${ }^{1,2}$ \\ 1 Department of Pharmacology, Faculty of Pharmacy, Mahidol University, Bangkok, Thailand \\ 2 Centre of Biopharmaceutical Science for Healthy Ageing, Faculty of Pharmacy, Mahidol University, Bangkok, Thailand
}

\begin{abstract}
Platelets, the cytoplasmic fragments of megakaryocytes, play a primary role in hemostasis. In addition, current evidence demonstrates the contribution of platelets in inflammation. Platelet-associated cell surface proteins (e.g. CD40L, P-selectin, GPVI and CLEC-2) and secretory molecules (e.g. PF4 and RANTES) regulate inflammatory response in various conditions, including cardio-cerebrovascular diseases, inflammatory bowel disease, rheumatoid arthritis and infection/sepsis. Anti-platelets and anti-inflammatory drugs have been shown to reduce the expression and/or function of these platelet-derived molecules, in association with the improved clinical outcomes in patients with inflammatory diseases. Moreover, the novel anti-inflammatory agents that act against platelet-specific targets have been being developed, which might be a potential therapeutic approach in thrombo-inflammatory diseases.
\end{abstract}

\section{Keywords:}

Platelets, CD40L, P-selectin, Platelet-derived chemokines, ITAM-associated receptors

\section{INTRODUCTION}

Since 1865 , platelet have been recognized to play a physiological role in hemostasis ${ }^{1}$. However, platelet overactivation leads to detrimental blood vessel occlusion, which contributes to the pathogenesis of thrombotic diseases ${ }^{2}$. Recently, the growing evidence has illustrated that platelets not only generate hemostatic plug but also stimulate the inflammatory responses. In atherosclerosis, platelets recruit immune cells to the site of plague rupture ${ }^{3,4}$. Furthermore, platelets act as a key player in various inflammatory diseases ${ }^{4,5}$. Interestingly, it has been demonstrated that anti-platelet therapy (e.g. aspirin and clopidogrel) attenuated inflammation and leukocyte infiltration in atherosclerosis ${ }^{3}$ and nonatherosclerotic inflammatory conditions, including in experimental models of inflammatory bowel disease (IBD $^{6}$, acute lung injury ${ }^{7}$, and chronic renal injury ${ }^{8}$. This review discusses the relevant mechanisms how platelets regulate inflammation and describes the role of platelet-derived molecules in various inflammatory conditions. The impact of antiplatelets, anti-inflammatory agents and potential drug candidates on the expression and function of platelet-specific inflammatory molecules is also addressed.

\section{INTERACTION BETWEEN PLATELETS, LEUKOCYTES AND ENDOTHELIAL CELLS DURING INFLAMMATION}

Basically, inflammatory process describes the movement of leukocytes toward the site of inflammation to fight against invading pathogens or to repair tissue damage $^{9}$. At present, it has been shown that platelets are recruited during the early phase of inflammation. Instead of forming hemostatic aggregates, platelets interact with endothelial cells, endothelial-lining gaps and preceded endothelial-adhered leukocytes, facilitating vascular permeability as well as leukocyte recruitment and activation ${ }^{10}$. Several platelet-expressed molecules have been recently reported to mediate this process (Figure 1), depending on specific inflammatory context. Furthermore, platelets are able to release microparticles containing proinflammatory molecules which contribute

\section{*Corresponding author}

*Surasak Wichaiyo surasak.wic@mahidol.ac.th 


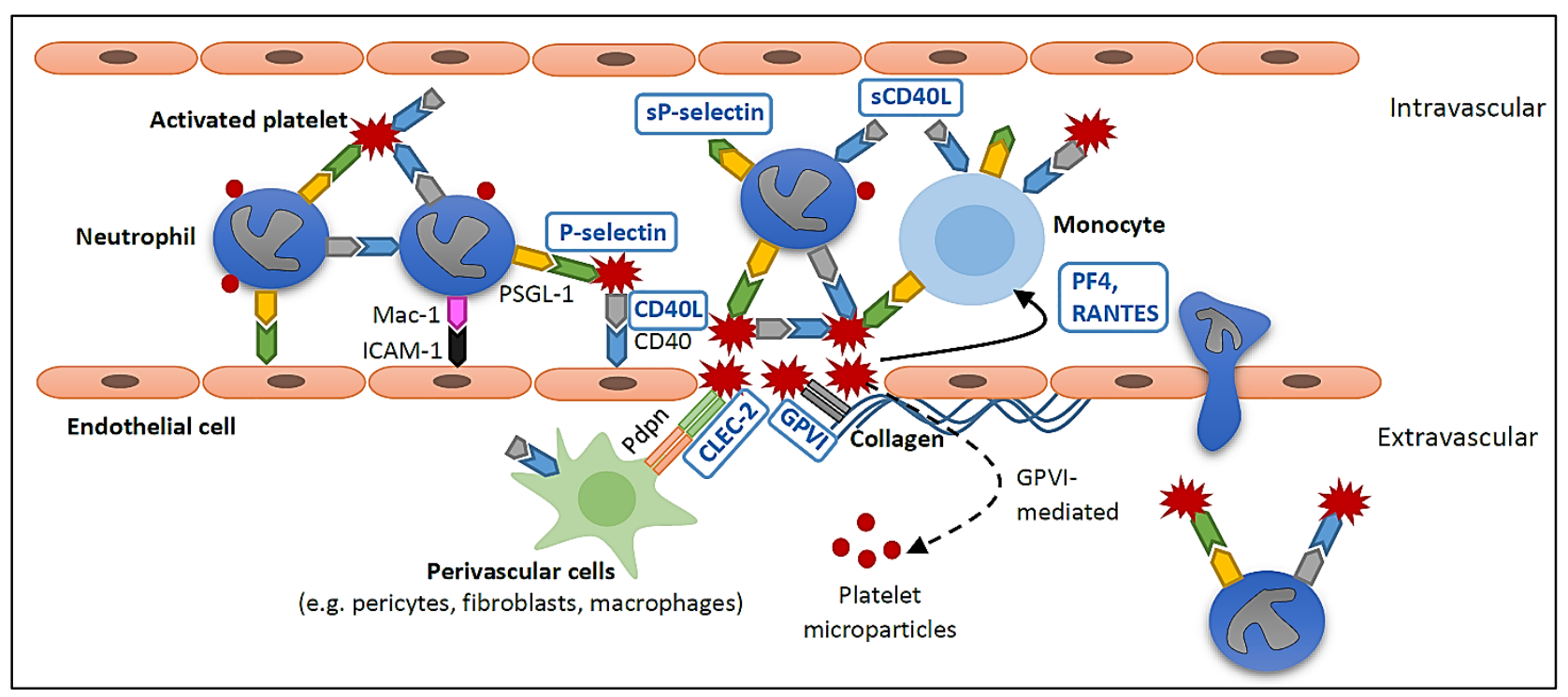

Figure 1. Interaction between platelets, leukocytes, and endothelial cells during thrombo-inflammation. Various platelet-derived molecules contribute to inflammatory response. Platelet-expressed CD40L binds CD40 on cell surface of other platelets or endothelial cells or leukocytes (e.g. neutrophils and monocytes) which is not only contributing to leukocyte arrest but also capable of activating these cells. Moreover, sCD40L released from platelets remains active in stimulating CD40. Similarly, platelet P-selectin is present in both membrane-bound and soluble forms. It interacts PSGL-1, providing leukocyte tethering. In addition, P-selectin-PSGL-1 interaction, resulting in leukocyte activation (e.g. Mac-1 expression for firm adhesion to endothelial cell and for inflammatory cytokine secretion). Furthermore, platelet releases chemokines such as PF4 (to stimulate pathogen killing activity of leukocytes) and RANTES (as chemotactic agent). Platelet ITAM-associated receptors also play a part in inflammation, particularly in the setting of exposed subendothelial layer. For example, GPVI-collagen interaction mediates the release of platelet microparticles while CLEC-2 binds podoplanin-expressing perivascular cells, which possibly regulates inflammation. Noticeably, extravascular migration of intact platelets (along with leukocytes) is observed in some conditions, contributing to the inflammatory response. CD40 = cluster of differentiation 40, CD40L = CD40 ligand, $\mathrm{SCD} 40 \mathrm{~L}=$ soluble CD40 ligand, PSGL-1 = P-selectin glycoprotein ligand-1, Mac-1 = macrophage -1 antigen, PF4 = platelet factor-4, RANTES $=$ regulated upon activation, normal T cell expressed and secreted, ITAM = immunoreceptor tyrosine-based activation motif, GPVI = glycoprotein VI, CLEC-2 = C-type lectin-like receptor 2, Pdpn = podoplanin .

Table 1. Representative platelet-derived molecules and their functions ${ }^{4,14,15}$.

\begin{tabular}{lll}
\hline \multicolumn{1}{c}{ Sources } & \multicolumn{1}{c}{ Molecules } & \multicolumn{1}{c}{ Known functions } \\
\hline Membrane proteins & $\begin{array}{l}\text { Receptors for primary agonists, glycoproteins (e.g. } \\
\text { GPVI), P-selectin, CD40L, CLEC-2 }\end{array}$ & $\begin{array}{l}\text { Various functions, including platelet activation } \\
\text { and inflammation (e.g. leukocytes recruitment) }\end{array}$ \\
\cline { 2 - 3 } & Secreted microparticles & $\begin{array}{l}\text { Various functions, including platelet } \\
\text { activation/inhibition }\end{array}$ \\
\hline $\begin{array}{lll}\text { Biologically active } \\
\text { metabolites (molecules that } \\
\text { is synthesized by activated } \\
\text { platelets) }\end{array}$ & Thromboxane $\mathrm{A}_{2}$ & Strong amplifier of platelet activation \\
\cline { 2 - 3 } & Sphingolipids e.g. sphingosine-1 phosphate & Mitogenesis, osteoclast differentiation \\
\cline { 2 - 3 } & Lysophosphatidic acid & Endothelial cell migration \\
\cline { 2 - 3 } & Platelet-activating factor & $\begin{array}{l}\text { Cell migration (endothelial cell, leukocytes), } \\
\text { Toll-like receptor ligands }\end{array}$ \\
\cline { 2 - 3 } $\begin{array}{l}\text { Secretion from dense } \\
\text { granules }\end{array}$ & Leukotriene $\mathrm{B}_{4}$ & Toll-like receptor ligands \\
& - ADP, ATP, inorganic PO4, PPi & $\begin{array}{l}\text { Primarily regulate platelet } \\
\text { activation/aggregation }\end{array}$ \\
\hline
\end{tabular}

Contents from $\alpha$ granules $\quad$ - Adhesive proteins e.g. vWF+ pro-peptide, fibrinogen, Primarily contribute to coagulation process fibronectin

- Clotting factors (e.g. factor V/Va, XI) and their

inhibitors (e.g. protein S)

- Fibrinolytic factors (e.g. plasminogen, u-PA) and their

inhibitors (e.g. PAI-1)

\begin{tabular}{ll}
\hline $\begin{array}{l}\text { Proteases (e.g. MMPs, ADAMs) and their inhibitors } \\
\text { (e.g. TIMPs 1-4) }\end{array}$ & Cell migration and angiogenesis \\
\hline Growth factors (e.g. PDGF, VEGF, IGF-1) & Cell growth and angiogenesis \\
\hline Chemokines and cytokines (e.g. PF4, TGF- $\beta 1$, IL-1, IL-8) & Inflammation and cell growth \\
\hline $\begin{array}{l}\text { Antimicrobial proteins (e.g. thrombocidins, kinocidins } \\
\text { and microbicidal cytokines, including RANTES) }\end{array}$ & Inflammation (e.g. leukocyte recruitment) \\
\hline
\end{tabular}

$\mathrm{ADP}=$ adenosine diphosphate, $\mathrm{ATP}=$ adenosine triphosphate, 5-HT = 5-hydroxytryptamine (or serotonin), $\mathrm{PPi}=$ pyrophosphate, $\mathrm{vWF}=\mathrm{von}$ Willebrand factor, PAI-1 = plasminogen activator inhibitor-1, MMPs $=$ matrix metalloproteinases, $\mathrm{ADAMs}=\mathrm{A}$ disintegrin and metalloproteases, TIMPs $=$ Tissue inhibitors of metalloproteinases, PDGF $=$ platelet-derived growth factor, VEGF $=$ vascular endothelial growth factor, IGF-1 = insulin-like growth factor $1, \mathrm{PF} 4=$ platelet factor- 4 , TGF- $\beta 1=$ transforming growth factor $-\beta 1$, IL = interleukin, RANTES = regulated upon activation, normal $\mathrm{T}$ cell expressed and secreted, $\mathrm{CD} 40 \mathrm{~L}=$ cluster of differentiation 40 ligand, CLEC-2 = C-type lectin-like receptor 2 
to pathogenesis of inflammatory diseases ${ }^{4,5,10,11}$. Interestingly, extravasation of platelets (along with leukocytes) has been observed in inflammatory conditions (e.g. in experimental models of inflammatory bowel disease ${ }^{12}$, allergic asthma ${ }^{13}$ and acute lung injury ${ }^{7}$ ), which is proposed to mediating tissue inflammation.

\section{PLATELET-EXPRESSED MOLECULES AND THEIR ROLE IN INFLAMMATION}

Several surface proteins (e.g. receptors and adhesion molecules) are constitutively expressed on resting platelets, and some of them are expressed upon activation. In addition, data of proteomic technology indicate that more than 300 proteins are secreted from a single activated platelet (Table 1) $)^{4,14-17}$. Moreover, platelet contains thousands of (pre)-mRNA which are capable of translating into proteins. The changes of platelet mRNA expression have also been observed in human disease $\mathrm{e}^{4,18}$. With the complex role of platelets in inflammation, this review focuses on six potential platelet-expressed inflammatory-associated molecules, including cluster of differentiation 40 ligand (CD40L), P-selectin, platelet factor-4 (PF4), regulated upon activation, normal $\mathrm{T}$ cell expressed and secreted (RANTES) chemokine, glycoprotein VI (GPVI) and Ctype lectin-like receptor 2 (CLEC-2) (,5,19,20. $^{2}$

\subsection{CD40L (also known as CD154)}

CD40L belongs to the tumor necrosis factor $\alpha$ (TNF- $\alpha$ ) family. It is a transmembrane glycoprotein which is expressed on activated $\mathrm{CD}^{+}$T-cells, monocytes, macrophages, endothelial cells, mast cells and platelets ${ }^{21}$. In resting platelets, CD40L is located, at $\alpha$-granule membrane, inside the cell. Upon platelet activation by agonists (e.g. thrombin, collagen, adenosine diphosphate $[\mathrm{ADP}]$ and thromboxane $\mathrm{A}_{2}\left[\mathrm{TXA}_{2}\right]$ ), CD40L is rapidly translocated to cell surface which is then cleaved (in minutes to hours) by matrix metalloproteinases (MMPs). As a result, soluble CD40L (sCD40L) is released from platelet cell surface ${ }^{4,22,23}$. GPIIb/IIIa (or integrin $\alpha \operatorname{IIb} \beta 3$ ) may also promote the cleavage of $\mathrm{CD} 40 \mathrm{~L}^{22}$. To mediate physiological functions, a trimeric active form of either membrane-bound CD40L or sCD40L binds to its receptor (CD40), which is widely expressed (e.g. on activated $\mathrm{CD} 4{ }^{+} \mathrm{T}$-cells, B-cells, monocytes, macrophages, neutrophils, dendritic cells, endothelial cells, mast cells, platelets, smooth muscle cells, fibroblasts and keratinocytes). The potential functions of CD40L are a $^{4,5,21,24}$;

(1) SCD40L binds CD40 on cell surface of platelet itself, results in platelet activation (e.g. the secretion of serotonin and $\beta$-thromboglobulin as well as the expression of P-selectin). In addition, sCD40L can bind GPIIb/IIIa, which subsequently activate platelets and stabilize the thrombus.

(2) The interaction of CD40L with CD40 on endothelial plasma membrane leads to increase the number of adhesion molecules (e.g. E-selectin, intercellular adhesion molecule-1 [ICAM-1] and vascular cell adhesion molecule-1 [VCAM-1]), which facilitate the adhesion of circulatory neutrophils and $\mathrm{T}$ cells at the vessel wall. Moreover, pro-inflammatory cytokines and chemokines (e.g. interleukin-6 [IL-6], IL-8, monocyte chemoattractant protein-1 [MCP-1] and RANTES) are secreted from CD40L-activated endothelial cells. These pro-inflammatory mediators involve monocyte and neutrophil recruitment.

(3) CD40L can also stimulate cytokine release from macrophages (e.g. IL-1 $\beta$, IL-6, IL-12 and TNF- $\alpha$ ), contributing to inflammatory processes.

\subsection{P-selectin (also known as CD62P)}

P-selectin is a glycoprotein which is expressed on platelets and endothelial cells. Constitutively, it is located as transmembrane protein at dense and $\alpha$ granules of resting platelets. Within minutes upon activation by platelet agonists, the increased numbers of P-selectin are translocated to platelet cell surface. It has been estimated that activated platelet expressed 10 times higher density of P-selectin on its cell surface, compared with activated endothelial cell ${ }^{25}$. Furthermore, $\mathrm{P}$-selectin exists in an active soluble form, either as a result of alternative mRNA splicing or MMP cleavage ${ }^{4,25}$. Both membrane-bound and soluble P-selectins bind Pselectin glycoprotein ligand-1 (PSGL-1) on leukocytes. P-selectin not only plays a role in leukocyte adhesion and rolling at the vessel wall but also stimulates signaling downstream of PSGL-1-barring leukocytes ${ }^{4}$, 26. For example, the binding of P-selectin and PSGL-1 enhances expression of macrophage-1 antigen (Mac-1) on leukocytes, thereby facilitating a firm adhesion between leukocytes and endothelial cells (via Mac-1ICAM-1 interaction ${ }^{26,27}$. In addition, P-selectin has been demonstrated to promote cytokine release from monocytes (e.g. TNF- $\alpha$, IL-1 $\beta$, IL-6, IL-8, IL-12 and

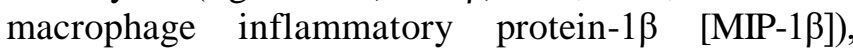
potentiating the inflammatory cascade ${ }^{26,28}$. As mentioned, platelet CD40L-CD40 interaction also induces P-selectin expression, which possibly enables the formation of platelet-leukocyte aggregates at the site of inflammation ${ }^{5}$.

\subsection{PF4 and RANTES chemokines}

PF4 (also known as chemokine (C-X-C motif) ligand 4 [CXCL4]) is a platelet-derived chemokine, which is secreted (within minutes) from $\alpha$-granule upon agonist-mediated platelet activation (e.g. thrombin, ADP and arachidonic acid). To a much lesser extent, 
PF4 is secreted by other cells, including macrophages, microglia, $\mathrm{T}$ cells and smooth muscle cells ${ }^{29,30}$. Although PF4 receptor is not clearly identified, it has been shown that PF4 enhances neutrophil adhesion to endothelial cell. However, PF4 is unlikely to produce chemotactic activity. Rather, it appears to activate host defense mechanism against invading microorganisms by stimulating the activity of monocytes/macrophages, including phagocytosis and ROS generation (in a strong and long-lasting manner $)^{29-31}$.

Platelets are a major source of RANTES (also known as chemokine (C-C motif) ligand 5 [CCL5]) although this chemokine is expressed in several cell types, especially $\mathrm{CD}^{+} \mathrm{T}$ lymphocytes ${ }^{5,32}$. RANTES is rapidly released, along with $\mathrm{PF} 4$, upon platelet activa$\operatorname{tion}^{31,33}$. Unlike PF4, RANTES is a strong chemotactic agent for monocytes. The CC chemokine receptor 5 (CCR5), which is expressed on monocytes, T lymphocytes and activated endothelial cells, is one of the receptors contributing to RANTES-mediated leukocyte chemotaxis. In addition, RANTES accumulates on endothelial cells of inflamed vessels through binding with glycosaminoglycans, resulting in RANTES immobilization which further allows leukocyte arrest ${ }^{31,33}$. Noticeably, RANTES secretion is observed upon stimulation by CD40L ${ }^{4}$.

\subsection{GPVI and CLEC-2}

GPVI is specifically expressed on cell surface of megakaryocytes and platelets. It acts as a receptor for collagen and laminin, the component of subendothelial matrix ${ }^{34,35}$. To provide a high affinity for collagen binding, GPVI associates with a dimer of FcR- $\gamma$ chain, and this GPVI-FcR- $\gamma$ chain complex further undergoes dimerization. Upon receptor activation, the immunereceptor tyrosine-based activation motif (ITAM) region (i.e. two YXXL sequences, located 6-12 amino acids apart) on FcR- $\gamma$ chain is phosphorylated by sarcoma (Src) family kinases, allowing the binding and activation of spleen tyrosine kinase (Syk). This enzyme then stimulates downstream molecules such as phospholipase $\mathrm{C} \gamma 2$ (PLC $\gamma 2$ ), which involves platelet activation (e.g. ADP and $\mathrm{TXA}_{2}$ secretion). GPVI primarily mediates hemostasis and thrombosis. In addition, it functions in vascular repair to prevent inflammation-mediated bleeding ${ }^{34,35}$. Interestingly, GPVI appears to play pro-inflammatory role during inflammation. For example, GPVI stimulates platelet microparticle generation, which subsequently contributes to inflammatory reaction in arthritis model ${ }^{11}$. During skin inflammation, it also promotes polarization of macrophages to M1 inflammatory phenotype ${ }^{36}$.

CLEC-2 is a new receptor identified for a decade. Unlike GPVI, CLEC-2 has only a single YXXL sequence (called hemITAM) on its own structure. This transmembrane protein is highly expressed as homodimer on megakaryocyte/platelet lineages. It is also present in lower extent on neutrophils, monocytes, dendritic cells, natural killer cells, macrophages, Kupffer cells and liver sinusoidal endothelial cells ${ }^{34,37}$. Activation of platelet CLEC-2 results in stimulation of Syk or Src, which subsequently mediates the function of downstream molecules, including PLC $\gamma 2$. So far, podoplanin is the only identified endogenous CLEC-2 ligand whereas the exogenous ligands include snake venom toxin called 'rhodocytin' and brown seaweedderived sulfated polysaccharide called 'fucoidan' $34,37,38$. Podoplanin is a transmembrane glycoprotein, mainly expressed on perivascular cells and mostly extravascular sites. These include pericytes, fibroblasts, macrophages, kidney podocytes, type I alveolar epithelial cells, lymphatic endothelial cells and several types of tumor cell $^{34,37,39,40}$. It has been reported that platelet CLEC-2 contributes to lung development and the separation of blood and lymphatic vessels during embryonic development ${ }^{34,37,39}$. CLEC-2 on platelet possibly interacts to its ligand (e.g. podoplanin), inducing platelet activation/ aggregation and regulating inflammatory response ${ }^{40}$. It has been demonstrated in vivo that CLEC-2-podoplanin interaction plays anti-inflammatory activity during inflammation, including acute lung injury ${ }^{41}$ and sepsis $^{42}$. In addition to GPVI, platelet CLEC-2 functions in vascular repair, possibly via binding to perivascular podoplanin-expressing cells, preventing hemorrhage generated by inflammatory reaction (e.g. following leukocyte diapedesis $)^{40,43}$. However, CLEC- 2 contributes to thrombus formation within hepatic micro-vessels in animal model of Salmonella typhimurium infection ${ }^{44}$. Podoplanin-expressing tumors, once enter blood circulation, may bind platelet CLEC-2. This platelettumor cell interaction protects against shear rateinduced cell damage and NK cell-mediated cytolysis, which allows tumor metastasis ${ }^{34,37,39,45}$.

\section{THE CONTRIBUTION OF PLATELET-DERIVED MOLECULES IN INFLAMMATORY DISEASES}

Several lines of evidence examine the function of platelets in inflammatory diseases, including cardiovascular and cerebrovascular diseases, autoimmune diseases, infection and sepsis ${ }^{4,5}$. The roles of aforementioned six platelet-derived molecules in inflammatory conditions are described in the following section. In addition, the effects of cardiovascular drugs (mainly antiplatelets), anti-inflammatory agents (Table 2 ) and potential novel drug candidates (Table 3 ) on the expression or function of these proteins are discussed.

\subsection{CD40L in inflammatory diseases}

The elevation of CD40L, which contributes to 
Table 2. Alterations of platelet-associated inflammatory molecules during disease progression and following drug treatment.

\begin{tabular}{|c|c|c|c|c|c|c|c|}
\hline \multicolumn{2}{|c|}{ Inflammatory settings } & CD40L & P-selectin & PF4 & RANTES & GPVI & CLEC-2 \\
\hline \multirow[t]{2}{*}{ CVD } & - During disease & $\uparrow^{21,46,47}$ & $\uparrow 25$ & $\leftrightarrow^{72}$ & $\uparrow 33$ & $\begin{array}{l}\uparrow(\text { surface })^{85,86} \\
\uparrow(\text { soluble })^{87}\end{array}$ & $\begin{array}{l}\uparrow(\text { surface })^{92} \\
\uparrow(\text { soluble })^{93}\end{array}$ \\
\hline & - Drug effects & $\begin{array}{l}\downarrow \mathrm{Clo}^{3}, \mathrm{Abci}^{46}, \\
\text { Statins }^{47}, \mathrm{Rosi}^{48}\end{array}$ & $\begin{array}{l}\downarrow \mathrm{Clo}^{3,25}, \text { ACEI } \\
\& \mathrm{CCB}^{3,25} \\
\text { Statins }^{3,25}, \text { Rosi }^{63}\end{array}$ & ND & $\begin{array}{l}\downarrow \mathrm{Clo}^{74}, \text { High- } \\
\text { dose statins }{ }^{73}\end{array}$ & $\begin{array}{l}\downarrow \text { Soluble level: } \\
\text { ASA }^{87} \\
\downarrow \text { Activity: Rosi }{ }^{88} \text {, } \\
\text { Losa }^{89}\end{array}$ & ND \\
\hline \multirow[t]{2}{*}{ IBD } & - During disease & $\begin{array}{l}\uparrow 50,51 \text { (not } \\
\text { platelet- } \\
\text { specific) }\end{array}$ & $\uparrow 66$ & $\uparrow 76$ & $\leftrightarrow^{77}$ & ND & ND \\
\hline & - Drug effects & $\downarrow_{\text {Inf }}^{52}$ & ND & ND & $\downarrow 5-\mathrm{ASA}^{77}$ & ND & ND \\
\hline \multirow[t]{2}{*}{$\mathbf{R A}$} & - During disease & $\begin{array}{l}\uparrow^{54} \text { (not platelet- } \\
\text { specific) }\end{array}$ & $\uparrow 67$ & $\uparrow 78$ & $\begin{array}{l}\uparrow^{79} \text { (not platelet- } \\
\text { specific) }\end{array}$ & ND & ND \\
\hline & - Drug effects & $\downarrow$ Pred $^{54}$ & ND & ND & $\begin{array}{l}\downarrow \mathrm{Eta}^{80}, \mathrm{Lef}^{81}, \\
\mathrm{MTX}^{82}\end{array}$ & $\begin{array}{l}\downarrow \text { Activity: ASA }+ \\
\text { Clo (animal study) } \\
\end{array}$ & ND \\
\hline \multirow[t]{2}{*}{$\begin{array}{l}\text { Infection/ } \\
\text { sepsis }\end{array}$} & - During disease & $\begin{array}{l}\uparrow^{56} \text { (not platelet- } \\
\text { specific) }\end{array}$ & $\uparrow 58,68,69$ & ND & ND & $\uparrow(\text { soluble })^{97}$ & ND \\
\hline & - Drug effects & $\begin{array}{l}\downarrow \text { Statins (animal } \\
\text { study) }\end{array}$ & $\begin{array}{l}\downarrow \text { Clo (animal } \\
\text { study) }\end{array}$ & ND & ND & ND & ND \\
\hline
\end{tabular}

Data are derived from human studies unless indicated. Clo = clopidogrel, Abci $=$ abciximab, Rosi $=$ rosiglitazone, ACEI $=$ angiotensinconverting enzyme inhibitor, $\mathrm{CCB}=$ calcium channel blocker, ASA $=$ aspirin, Losa $=$ losartan, Inf $=$ infliximab, 5-ASA $=5$-aminosalicylic acid, Pred = prednisolone, Eta $=$ Etanercept, Lef $=$ leflunomide, $\mathrm{MTX}=$ methotrexate, $\mathrm{ND}=$ no data, surface $=$ membrane-bound form, soluble $=$ soluble form, $\uparrow=$ increased, $\downarrow=$ decreased, $\leftrightarrow=$ unchanged. References as superscript.

Table 3. Examples of drug candidates that target platelet-derived molecules in thrombo-inflammatory diseases.

\begin{tabular}{|c|c|c|c|}
\hline Targets & Candidate molecules & Mechanism of action & Status of development \\
\hline \multirow[t]{4}{*}{ CD40L } & - VIB4920 (MEDI4920) ${ }^{53}$ & $\begin{array}{l}\text { - A fusion protein that blocks interaction } \\
\text { between CD40L and CD40 }\end{array}$ & - Phase I clinical trial in RA \\
\hline & - Dapirolizumab pegol ${ }^{53}$ & - Anti-CD40L monoclonal antibody & $\begin{array}{l}\text { - Phase II clinical trial in systemic lupus } \\
\text { erythematosus }\end{array}$ \\
\hline & - CFZ533, BI-655064 & $\begin{array}{l}\text { - Monoclonal antibodies that inhibit CD40, a } \\
\text { receptor of CD40L }\end{array}$ & - Phase II clinical trial in RA \\
\hline & $-\operatorname{ch} 5 \mathrm{D} 12, \mathrm{FFP} 104^{53}$ & $\begin{array}{l}\text { - Monoclonal antibodies that inhibit CD40, a } \\
\text { receptor of CD40L }\end{array}$ & - Phase II clinical trial in Chron's disease \\
\hline P-selectin & - Crizanlizumab ${ }^{65}$ & - Anti-P-selectin monoclonal antibody & $\begin{array}{l}\text { - Approved by US FDA for the } \\
\text { prevention of vaso-occlusive crises in } \\
\text { patients with sickle cell disease }\end{array}$ \\
\hline \multirow[t]{3}{*}{ RANTES } & - Met-RANTES antibody ${ }^{33}$ & - Inhibits CCR5, a receptor of RANTES & - Animal model of atherosclerosis \\
\hline & - [44AANA47]-RANTES ${ }^{75}$ & $\begin{array}{l}\text { - A variant RANTES with specific mutation } \\
\text { that inhibits oligomerization after binding } \\
\text { with endogenous RANTES }\end{array}$ & - Animal model of atherosclerosis \\
\hline & - MKEY peptide ${ }^{84}$ & $\begin{array}{l}\text { - Inhibits PF4-RANTES heteromer } \\
\text { formation }\end{array}$ & $\begin{array}{l}\text { - Animal model of sepsis- or acid- } \\
\text { induced acute lung injury }\end{array}$ \\
\hline PF4 & - MKEY peptide ${ }^{84}$ & $\begin{array}{l}\text { - Inhibits PF4-RANTES heteromer } \\
\text { formation }\end{array}$ & $\begin{array}{l}\text { - Animal model of sepsis- or acid- } \\
\text { induced acute lung injury }\end{array}$ \\
\hline GPVI & - Glenzocimab (ACT017) $)^{90,91}$ & - Anti-GPVI monoclonal antibody & - Phase II clinical trial in ischemic stroke \\
\hline CLEC-2 & - Cobalt hematoporphyrin 95 & - Inhibits CLEC-2 & $\begin{array}{l}\text { - Animal model of arterial and venous } \\
\text { thrombosis } \\
\text { - Animal model of cancer metastasis }\end{array}$ \\
\hline
\end{tabular}

US FDA = United States of America Food and Drug Administration, RA = Rheumatoid arthritis

chronic inflammation, has been reported in patients with cardiovascular diseases, including atherosclerosis and diabetes (both type 1 and 2). In addition, the increase in plasma level of sCD40L signifies the high risk of adverse cardiovascular events in these patients ${ }^{21}$, 46,47. Clopidogrel (a P2Y 12 ADP-receptor antagonist) ${ }^{3}$, abciximab (a GPIIb/IIIa inhibitor) ${ }^{46}$, statins (hydroxymethylglutaryl-coenzyme A [HMG-CoA] reductase inhibitors) ${ }^{47}$ and rosiglitazone (peroxisome proliferatoractivated receptor gamma [PPAR $\gamma]$ agonists $)^{48}$ have shown to reduce sCD40L level in patients with atherosclerosis and/or diabetes (Table 2), whereas the effect of aspirin (a cyclooxygenase-1 [COX-1] inhibitor) is controversial ${ }^{3}$. Moreover, in mouse model of atherosclerosis, anti-CD40L monoclonal antibody reduces size and number of atherosclerotic plagues, number of macrophages, T-lymphocytes and lipid content within the plagues ${ }^{47}$. However, there is no current development of anti-CD40L antibody for the treatment of atherosclerosis, possibly because it could promote thrombotic events ${ }^{49}$. 
During an active phase of inflammatory bowel disease (IBD), a chronic inflammation of intestinal tract, it has been found that platelet count in patients was higher than $450 \times 10^{9} / \mathrm{L}$, which is called "reactive thrombocytosis". In addition, activated platelets appear to involve in the pathogenesis of inflamed colons ${ }^{4,5,50}$. Platelets were observed, colocalized with polymorphonuclear neutrophils, in crypt abscesses of IBD patients ${ }^{5,12}$. sCD40L and membrane-bound CD40L are upregulated in IBD patients (both ulcerative colitis and Crohn's disease) compared with healthy controls (Table $2)^{50,51}$. In addition, sCD40L is postulated to link the inflammation and thromboembolic complication (thrombo-inflammation) in IBD patients ${ }^{51}$. Treatment with infliximab (anti-TNF- $\alpha$ chimeric monoclonal antibody) has demonstrated to reduce CD40L expression and $\mathrm{SCD} 40 \mathrm{~L}$ secretion in IBD patients (Table 2). However, peripheral blood T-cells appear to be the major source of sCD40L in this study. This could be due to a limited capacity of platelets (anucleate cells) in producing new proteins, in contrast to activated T-cells which play a predominant role for the production of inflammatory mediators in chronic (long-term) inflammation $^{52}$. Clopidogrel has been reported to reduce inflammation in rat models of IBD. However, the changes in expression or function of platelet-derived molecules have not been measured ${ }^{6}$. More recently, the monoclonal antibodies against $\mathrm{CD} 40$, a receptor of CD40L, have been shown to inhibit inflammation in IBD and being studied in patients with Chron's disease $(\text { Table } 3)^{53}$.

In rheumatoid arthritis (RA), an autoimmune disease primarily affects peripheral joints, it has been revealed that plasma CD40L level is higher, especially in patients with vasculitis, compared with controls (Table 2). However, such elevated SCD40L has not been identified as platelet-origin. Notably, sCD40L level in vasculitis RA patients is decreased after treatment with prednisolone for 2-4 weeks (although some patients receive plasmapheresis $)^{54}$. At present, antibodies ${ }^{53}$ and synthetic molecules ${ }^{55}$ targeting CD40L-CD40 interaction have been shown to reduce pathogenic inflammation in RA, and some of them are being investigated in Phase II clinical studies (Table 3$)^{53}$.

In patients with severe sepsis, sCD40L level is higher than healthy controls (Table 2). In addition, non-survivors exhibit higher serum sCD40L than in survivors $^{56}$. In cecal ligation and puncture (CLP) mouse model of abdominal sepsis, the increased sCD40L level activates neutrophils in mediating acute lung injury ${ }^{57}$. Antiplatelets (e.g. aspirin, $\mathrm{P}_{2} \mathrm{Y}_{12}$ inhibitors and GPIIb/ IIIa inhibitors) have demonstrated the beneficial effects (e.g. the improvement in end-organ damage or mortality) in animal models of sepsis. In addition, several reports have revealed that antiplatelets (especially aspirin and clopidogrel) reduce mortality and the occurrence of acute lung injury in patients with sepsis ${ }^{58,59}$. However, it is unknown whether this effect correlates with CD40L expression. The role of statins in prevention and treatment of sepsis has also been studied ${ }^{60,61}$. Simvastatin reduces CD40L expression (Table 2) and prevents its shedding from platelet surface into the circulation, contributing to the attenuation of acute lung injury in CLP mice ${ }^{62}$.

\subsection{P-selectin in inflammatory diseases}

High level of soluble P-selectin is observed in various types of acute and chronic cardiovascular disease (e.g. hypertension, hypercholesterolemia, diabetes, coronary artery disease [CAD], ischemic stroke and atrial fibrillation). Antihypertensive drugs, including angiotensin-converting enzyme inhibitors and calcium channel blockers decrease both membrane-bound and soluble P-selectin in patients with hypertension (Table $2)^{25}$. In addition, rosiglitazone diminishes plasma Pselectin in diabetic patients ${ }^{63}$. Statin treatment in patients with hypercholesterolemia and stable CAD also attenuates P-selectin expression. Moreover, starting statin on admission in patients with acute coronary syndrome (ACS) appeared to lower P-selectin level at post-myocardial infarction ${ }^{25}$. Similarly, pretreatment with clopidogrel in patients with ACS has shown to reduce P-selectin after percutaneous coronary intervention (Table 2). A reduction of P-selectin is also observed following clopidogrel treatment in patients with diabetes and acute ischemic stroke (AIS) ${ }^{3,25}$.

Interestingly, the upregulation of P-selectin contributes to the pathological consequences of sickle cell disease. A sickled-shape red blood cell and subsequent hemolysis stimulates intravascular inflammatory response, including the expression of P-selectin on cell surface of activated endothelial cells and platelets, leading to aggregates of blood cells within the microvessels. This reaction causes vaso-occlusive pain crises and thrombosis in patients with sickle cell disease, which result in multi-organ damage ${ }^{64,65}$. Crizanlizumab, a humanized anti-P-selectin monoclonal antibody (Table 3), has recently been approved for the prevention of vaso-occlusive crises in patients with sickle cell disease ${ }^{65}$.

Soluble P-selectin level is increased in active phase of IBD (Table 2$)^{66}$ whereas membrane-bound form is discovered to be upregulated on platelets of active RA patients, which is in contrast to a low level of expression in the remission phase as well as in controls (Table 2) ${ }^{67}$.

In patients with sepsis, it has been demonstrated that surface P-selectin ${ }^{58,68}$ and soluble P-selectin ${ }^{69}$ (Table 2) are elevated, which positively correlate with the severity of sepsis. In addition, the increased number of intravascular platelet-neutrophil interactions has been observed, which contributes to inflammatory 
response in sepsis ${ }^{58,68}$. In CLP mice, P-selectin has been shown to involve neutrophil migration, which plays a role in sepsis-induced acute renal injury ${ }^{70}$. Clopidogrel treatment reduces the $\mathrm{P}$-selectin level in these mice ${ }^{71}$

\subsection{PF4 and RANTES in inflammatory diseases}

It has recently been elucidated that the plasma PF4 level in patients with or without CAD are not different, possibly because of the local expression of PF4 within the atheroma. In addition, there is no correlation between plasma PF4 and plague progress$\operatorname{sion}^{72}$. RANTES is highly expressed at atherosclerotic plague, and its plasma level is contradictory in patients with CAD. The lower RANTES level was observed in stable CAD patients, compared with healthy controls whereas it was temporarily increased in unstable angina, compared with stable CAD patients ${ }^{33}$. High dose statins ${ }^{73}$ and clopidogrel ${ }^{74}$ have demonstrated to reduce plasma RANTES in stable CAD (Table 2). In atherosclerotic mice, CCR5 inhibitor (MET-RANTES antibody $^{33}$ ) or [44AANA47]-RANTES (a variant RANTES that prevents oligomerization of endogenous RANTES $)^{75}$ has been demonstrated to decrease infiltration of leukocytes and prevent the progression of atherosclerosis (Table 3).

In active IBD patients, it has been reported that plasma PF4 level is higher compared with controls. This elevated level of PF4 is maintained in clinically inactive phase of IBD during a 12-month period of follow-up, which may associate with pre-thrombotic state in $\mathrm{IBD}^{76}$. RANTES level is unaltered in patients with ulcerative colitis. However, 5-aminosalicylic acid (5-ASA) significantly decreases RANTES in these patients (Table 2) ${ }^{77}$.

During the course of RA, PF4 level is elevated in early phase compared with resolving phase $^{78}$. RANTES in serum and synovial fluid are also increased in RA relative to osteoarthritis patients. However, it remains unknown whether platelet is the predominant source of RANTES ${ }^{79}$. Etanercept (a soluble TNF- $\alpha$ receptor) ${ }^{80}$ and immunosuppressants, including leflunomide $^{81}$ and methotrexate ${ }^{82}$, significantly reduce serum RANTES in RA patients during 1 year of treatment (Table 2). The effect of infliximab on RANTES level is controversial ${ }^{79,83}$.

In patients with acute lung injury as well as in mouse models of sepsis (e.g. CLP mice), PF4 and RANTES formed heteromers, associating the pathogenesis of sepsis-induced acute lung injury (i.e. neutrophil infiltration, lung edema and lung tissue damage). A synthetic peptide MKEY, which inhibits PF4-RANTES heteromer formation (Table 3), has been shown to attenuate pathologic inflammation in animal model of acute lung imjury ${ }^{84}$.

\subsection{GPVI and CLEC-2 in inflammatory diseases}

The upregulation of GPVI on platelet surface (Table 2) is observed in patients with ACS before the occurrence of myocardial necrosis (the release of troponin and creatine kinase as biomarkers). Thus, GPVI is postulated as a potential biomarker to early identify the risk of myocardial infarction. Moreover, patients with elevated surface GPVI exhibit a pattern of high residual platelet reactivity after coronary stenting, even in the treatment with dual antiplatelets (aspirin plus clopidogrel). Higher percentage of these patients is classified as a low responder to clopidogrel ${ }^{85}$. In patients with transient ischemic attack and AIS, GPVI on platelet surface is also increased, and may contribute to poor clinical outcomes ${ }^{86}$. Furthermore, soluble GPVI (inactive form) is highly detected in plasma of patients with AIS, which might suggest the compensatory mechanism to reduce platelet reactivity to collagen. This elevated level of soluble GPVI is significantly decreased after 3 to 6 months of aspirin treatment ${ }^{87}$. Remarkably, the in vitro study has demonstrated that rosiglitazone inhibits collagen-mediated platelet aggregation by reducing the phosphorylation of several GPVI-associated signaling molecules (e.g. LAT, Akt/ PKB and PLC $\gamma 2$ ). In addition, it appears that the inactivated state of PPAR $\gamma$ generally associates with Syk and LAT, correlating the phosphorylation and activation of these molecules. Rosiglitazone, by activating PPAR $\gamma$, prevents this interaction, accompanied with a reduction of platelet aggregation ${ }^{88}$. Losartan (angiotensin II receptor blocker) produces a certain degree of antiplatelet activity via GPVI inhibition in vitro (Table 2$)^{89}$. At present, the antibodies against GPVI or other GPVI-inhibiting approaches have been developed as anti-thrombotic agents ${ }^{20}$. In particular, glenzocimab (ACT017), an anti-GPVI Fab, is currently investigated in phase II clinical trial for the treatment of ischemic stroke (Table 3) $)^{90,91}$.

A more recent phosphoproteomic study has shown that surface expression of platelet CLEC-2, together with GPVI, is upregulated in severe obesity (cardiovascular risk population) $^{92}$. In addition, high level of soluble CLEC-2 in plasma is observed in patients with CAD and ACS relative to healthy controls (Table 2), which is associated with the risk of $\mathrm{CAD}^{93}$. In mice, it has been recently shown that blocking CLEC-2podoplanin axis protects against deep vein thrombosis $^{94}$. Moreover, cobalt hematoporphyrin, a CLEC-2 inhibitor, could inhibit arterial and venous thrombosis without increased risk of bleeding in vivo (Table 3$)^{95}$.

In RA patients, GPVI has been reported to stimulate platelet microparticle generation, which is detected in the synovial fluid. These microparticles contribute to inflammatory reaction in $\mathrm{RA}^{11}$. In animal model, it has been demonstrated that either aspirin alone or dual antiplatelet therapy (aspirin plus clopidogrel) improves radiologic findings in rats with collagen- 
induced arthritis ${ }^{96}$

During sepsis, the increase in soluble GPVI is detected (Table 2), and may act as a biomarker in predicting sepsis progression and mortality in injured patients ${ }^{97}$. In contrast, the recent evidence demonstrates that CLEC-2-podoplanin interaction provide benefits by reducing inflammation in animal model of sepsis ${ }^{42}$ and acute lung injury ${ }^{41}$. However, inhibition of CLEC-2podoplanin axis could help alleviate thrombus formation in the liver in mice with Salmonella typhimurium infection ${ }^{44}$. Notably, the contribution of GPVI and CLEC-2 in infection/sepsis appears to be modeldependent and is currently the area of active investigation, particularly in vivo ${ }^{98}$.

\section{PERSPECTIVES}

It becomes clear that platelets play a potential role in inflammation. The contribution of various platelet-derived molecules in inflammatory response have been being reported. CD40L and P-selectin involve in various inflammatory diseases. This is possibly because these two molecules share a common function for the interaction between platelets, endothelial cells and leukocytes. PF4 and RANTES appear to play a role largely in immune dysregulation (e.g. IBD and RA) and infectious disease (e.g. sepsis). However, it remains unclear whether platelets are the only major source of these two inflammatory chemokines. Interestingly, GPVI is a promising target for cardio-cerebrovascular thrombosis, especially in patients with high residual platelet reactivity, in which clopidogrel treatment is less effective. Although the function of platelet CLEC-2 has been actively studied in various in vitro and in vivo preclinical models, including the role in thrombus stabilization and thrombo-inflammation, the evidence in patients with inflammatory diseases would provide better understanding for the role of platelet CLEC-2 in inflammation. Antiplatelets and other cardiovascular drugs have shown to reduce the level of CD40L, Pselectin and RANTES during inflammation. However, there is a lack of well-controlled clinical studies to support their use in practice, particularly in non-cardiovascular settings. With recent advances in development of novel drug candidates for the treatment of inflammatory conditions, and some of them are being investigated in clinical trials, therefore, it is possible that the specific platelet-targeted anti-inflammatory drugs would be available in the future.

\section{Conflict of interest}

The authors declare there are no conflicts of interest.

\section{Funding}

None to declare.

\section{Ethics approval}

None to declare.

\section{Article info:}

Received February 16, 2021

Received in revised form April 19, 2021

Accepted May 13, 2021

\section{REFERENCES}

1. Lievens D, von Hundelshausen P. Platelets in atherosclerosis. Thromb Haemost. 2011;106(5):827-38.

2. Rivera J, Lozano ML, Navarro-Nunez L, Vicente V. Platelet receptors and signaling in the dynamics of thrombus formation. Haematologica. 2009;94(5):700-11.

3. Steinhubl SR, Badimon JJ, Bhatt DL, Herbert JM, Luscher TF. Clinical evidence for anti-inflammatory effects of antiplatelet therapy in patients with atherothrombotic disease. Vasc Med. 2007;12(2):113-22.

4. Nurden AT. Platelets, inflammation and tissue regeneration. Thromb Haemost. 2011;105 Suppl 1: S13-33.

5. Stokes KY, Granger DN. Platelets: a critical link between inflammation and microvascular dysfunction. J Physiol. 2012; 590(5):1023-34.

6. Patel SH, Rachchh MA, Jadav PD. Evaluation of antiinflammatory effect of anti-platelet agent-clopidogrel in experimentally induced inflammatory bowel disease. Indian $\mathbf{J}$ Pharmacol. 2012;44(6):744-8.

7. Ortiz-Munoz G, Mallavia B, Bins A, Headley M, Krummel MF, Looney MR. Aspirin-triggered 15-epi-lipoxin A4 regulates neutrophil-platelet aggregation and attenuates acute lung injury in mice. Blood. 2014;124(17):2625-34.

8. Tu X, Chen X, Xie Y, Shi S, Wang J, Chen Y, et al. Antiinflammatory renoprotective effect of clopidogrel and irbesartan in chronic renal injury. J Am Soc Nephrol. 2008; 19(1):77-83.

9. Medzhitov R. Origin and physiological roles of inflammation. Nature. 2008;454(7203):428-35.

10. Gros A, Ollivier V, Ho-Tin-Noe B. Platelets in inflammation: regulation of leukocyte activities and vascular repair. Front Immunol. 2014;5:678.

11. Boilard E, Nigrovic PA, Larabee K, Watts GF, Coblyn JS, Weinblatt ME, et al. Platelets amplify inflammation in arthritis via collagen-dependent microparticle production. Science. 2010;327(5965):580-3.

12. Weissmuller T, Campbell EL, Rosenberger P, Scully M, Beck PL, Furuta GT, et al. PMNs facilitate translocation of platelets across human and mouse epithelium and together alter fluid homeostasis via epithelial cell-expressed ecto-NTPDases. J Clin Invest. 2008;118(11):3682-92.

13. Pitchford SC, Momi S, Baglioni S, Casali L, Giannini S, Rossi R, et al. Allergen induces the migration of platelets to lung tissue in allergic asthma. Am J Respir Crit Care Med. 2008;177(6): 604-12.

14. Semple JW, Italiano JE Jr, Freedman J. Platelets and the immune continuum. Nat Rev Immunol. 2011;11(4):264-74.

15. Schrottmaier WC, Mussbacher M, Salzmann M, Assinger A. Platelet-leukocyte interplay during vascular disease. Atherosclerosis. 2020;307:109-20.

16. Mezger M, Nording H, Sauter R, Graf T, Heim C, Von Bubnoff $\mathrm{N}$, et al. Platelets and Immune Responses During Thromboinflammation. Front Immunol. 2019;10:1731.

17. Margraf A, Zarbock A. Platelets in Inflammation and Resolution. J Immunol. 2019;203(9):2357-67.

18. Rowley JW, Schwertz H, Weyrich AS. Platelet mRNA: the meaning behind the message. Curr Opin Hematol. 2012;19(5): 385-91.

19. Nagy B Jr, Miszti-Blasius K, Kerenyi A, Clemetson KJ, 
Kappelmayer J. Potential therapeutic targeting of plateletmediated cellular interactions in atherosclerosis and inflammation. Curr Med Chem. 2012;19(4):518-31.

20. Dutting S, Bender M, Nieswandt B. Platelet GPVI: a target for antithrombotic therapy?!. Trends Pharmacol Sci. 2012;33(11): 583-90.

21. Rizvi M, Pathak D, Freedman JE, Chakrabarti S. CD40-CD40 ligand interactions in oxidative stress, inflammation and vascular disease. Trends Mol Med. 2008;14(12):530-8.

22. Andre P, Nannizzi-Alaimo L, Prasad SK, Phillips DR. Plateletderived CD40L: the switch-hitting player of cardiovascular disease. Circulation. 2002;106(8):896-9.

23. Enomoto Y, Adachi S, Matsushima-Nishiwaki R, Doi T, Niwa $\mathrm{M}$, Akamatsu S, et al. Thromboxane A(2) promotes soluble CD40 ligand release from human platelets. Atherosclerosis. 2010;209(2):415-21.

24. Hassan GS, Merhi Y, Mourad W. CD40 ligand: a neoinflammatory molecule in vascular diseases. Immunobiology. 2012;217(5):521-32.

25. Blann AD, Nadar SK, Lip GY. The adhesion molecule Pselectin and cardiovascular disease. Eur Heart J. 2003;24(24): 2166-79.

26. Andre P. P-selectin in haemostasis. Br J Haematol. 2004; 126(3):298-306.

27. Di Carlo E, Forni G, Lollini P, Colombo MP, Modesti A, Musiani P. The intriguing role of polymorphonuclear neutrophils in antitumor reactions. Blood. 2001;97(2):339-45.

28. Suzuki J, Hamada E, Shodai T, Kamoshida G, Kudo S, Itoh S, et al. Cytokine secretion from human monocytes potentiated by P-selectin-mediated cell adhesion. Int Arch Allergy Immunol. 2013;160(2):152-60.

29. Kasper B, Petersen F. Molecular pathways of platelet factor 4/CXCL4 signaling. Eur J Cell Biol. 2011;90(6-7):521-6.

30. Wang Z, Huang H. Platelet factor-4 (CXCL4/PF-4): an angiostatic chemokine for cancer therapy. Cancer Lett. 2013; 331(2):147-53.

31. Von Hundelshausen P, Petersen F, Brandt E. Platelet-derived chemokines in vascular biology. Thromb Haemost. 2007;97(5): 704-13.

32. Appay V, Rowland-Jones SL. RANTES: a versatile and controversial chemokine. Trends Immunol. 2001;22(2):83-7.

33. Winnik S, Klingenberg R, Matter CM. Plasma RANTES: a molecular fingerprint of the unstable carotid plaque? Eur Heart J. 2011;32(4):393-5.

34. Watson SP, Herbert JM, Pollitt AY. GPVI and CLEC-2 in hemostasis and vascular integrity. J Thromb Haemost. 2010; 8(7):1456-67.

35. Boulaftali Y, Hess PR, Getz TM, Cholka A, Stolla M, Mackman $\mathrm{N}$, et al. Platelet ITAM signaling is critical for vascular integrity in inflammation. J Clin Invest. 2013;123(2):908-16.

36. Pierre S, Linke B, Suo J, Tarighi N, Del Turco D, Thomas D, et al. GPVI and Thromboxane Receptor on Platelets Promote Proinflammatory Macrophage Phenotypes during Cutaneous Inflammation. J Invest Dermatol. 2017;137(3):686-95.

37. Suzuki-Inoue K, Inoue O, Ozaki Y. Novel platelet activation receptor CLEC-2: from discovery to prospects. J Thromb Haemost. 2011;9 Suppl 1:44-55.

38. Manne BK, Getz TM, Hughes CE, Alshehri O, Dangelmaier C, Naik UP, et al. Fucoidan is a novel platelet agonist for the Ctype lectin-like receptor 2 (CLEC-2). J Biol Chem. 2013;288(11): 7717-26.

39. Kerrigan AM, Navarro-Nunez L, Pyz E, Finney BA, Willment JA, Watson SP, et al. Podoplanin-expressing inflammatory macrophages activate murine platelets via CLEC-2. J Thromb Haemost. 2012;10(3):484-6.

40. Wichaiyo S, Lax S, Montague SJ, Li Z, Grygielska B, Pike JA, et al. Platelet glycoprotein VI and C-type lectin-like receptor 2 deficiency accelerates wound healing by impairing vascular integrity in mice. Haematologica. 2019;104(8):1648-60.
41. Lax S, Rayes J, Wichaiyo S, Haining EJ, Lowe K, Grygielska $\mathrm{B}$, et al. Platelet CLEC-2 protects against lung injury via effects of its ligand podoplanin on inflammatory alveolar macrophages in the mouse. Am J Physiol Lung Cell Mol Physiol. 2017;313(6): L1016-L29.

42. Rayes J, Lax S, Wichaiyo S, Watson SK, Di Y, Lombard S, et al. The podoplanin-CLEC-2 axis inhibits inflammation in sepsis. Nat Commun. 2017;8(1):2239.

43. Rayes J, Jadoui S, Lax S, Gros A, Wichaiyo S, Ollivier V, et al. The contribution of platelet glycoprotein receptors to inflammatory bleeding prevention is stimulus and organ dependent. Haematologica. 2018;103(6):e256-e8.

44. Hitchcock JR, Cook CN, Bobat S, Ross EA, Flores-Langarica A, Lowe KL, et al. Inflammation drives thrombosis after Salmonella infection via CLEC-2 on platelets. J Clin Invest. 2015;125(12):4429-46.

45. Lowe KL, Navarro-Nunez L, Watson SP. Platelet CLEC-2 and podoplanin in cancer metastasis. Thromb Res. 2012;129 Suppl 1:S30-7.

46. Heeschen C, Dimmeler S, Hamm CW, Van Den Brand MJ, Boersma E, Zeiher AM, et al. Soluble CD40 ligand in acute coronary syndromes. N Engl J Med. 2003;348(12):1104-11.

47. Zhang B, Wu T, Chen M, Zhou Y, Yi D, Guo R. The CD40/CD40L system: a new therapeutic target for disease. Immunol Lett. 2013;153(1-2):58-61.

48. Marx N, Imhof A, Froehlich J, Siam L, Ittner J, Wierse G, et al. Effect of rosiglitazone treatment on soluble CD40L in patients with type 2 diabetes and coronary artery disease. Circulation. 2003;107(15):1954-7.

49. Bosmans LA, Bosch L, Kusters PJH, Lutgens E, Seijkens TTP. The CD40-CD40L Dyad as Immunotherapeutic Target in Cardiovascular Disease. J Cardiovasc Transl Res. 2021;14(1): 13-22.

50. Danese S, Motte Cd Cde L, Fiocchi C. Platelets in inflammatory bowel disease: clinical, pathogenic, and therapeutic implications. Am J Gastroenterol. 2004;99(5):938-45

51. Koutroubakis IE, Theodoropoulou A, Xidakis C, Sfiridaki A, Notas G, Kolios G, et al. Association between enhanced soluble CD40 ligand and prothrombotic state in inflammatory bowel disease. Eur J Gastroenterol Hepatol. 2004;16(11):1147-52.

52. Danese S, Sans M, Scaldaferri F, Sgambato A, Rutella S, Cittadini A, et al. TNF-alpha blockade down-regulates the CD40/CD40L pathway in the mucosal microcirculation: a novel anti-inflammatory mechanism of infliximab in Crohn's disease. J Immunol. 2006;176(4):2617-24.

53. Karnell JL, Rieder SA, Ettinger R, Kolbeck R. Targeting the CD40-CD40L pathway in autoimmune diseases: Humoral immunity and beyond. Adv Drug Deliv Rev. 2019;141:92-103.

54. Tamura N, Kobayashi S, Kato K, Bando H, Haruta K, Oyanagi $\mathrm{M}$, et al. Soluble CD154 in rheumatoid arthritis: elevated plasma levels in cases with vasculitis. J Rheumatol. 2001;28(12):2583-90.

55. Chen J, Song Y, Bojadzic D, Tamayo-Garcia A, Landin AM, Blomberg BB, et al. Small-Molecule Inhibitors of the CD40CD40L Costimulatory Protein-Protein Interaction. J Med Chem. 2017;60(21):8906-22.

56. Lorente L, Martin MM, Perez-Cejas A, Ferreres J, Sole- Violan J, Labarta L, et al. Non-survivor septic patients have persistently higher serum sCD40L levels than survivors. J Crit Care. 2017;41:177-82

57. Rahman M, Zhang S, Chew M, Ersson A, Jeppsson B, Thorlacius H. Platelet-derived CD40L (CD154) mediates neutrophil upregulation of Mac-1 and recruitment in septic lung injury. Ann Surg. 2009;250(5):783-90.

58. De Stoppelaar SF, Van 't Veer C, Van Der Poll T. The role of platelets in sepsis. Thromb Haemost. 2014;112(4):666-77.

59. Akinosoglou K, Alexopoulos D. Use of antiplatelet agents in sepsis: a glimpse into the future. Thromb Res. 2014;133(2):131-8.

60. Dobesh PP, Olsen KM. Statins role in the prevention and treatment of sepsis. Pharmacol Res. 2014;88:31-40. 
61. Terblanche M, Almog Y, Rosenson RS, Smith TS, Hackam DG. Statins and sepsis: multiple modifications at multiple levels. Lancet Infect Dis. 2007;7(5):358-68.

62. Zhang S, Rahman M, Zhang S, Qi Z, Thorlacius H. Simvastatin antagonizes CD40L secretion, CXC chemokine formation, and pulmonary infiltration of neutrophils in abdominal sepsis. J Leukoc Biol. 2011;89(5):735-42.

63. Chu JW, Abbasi F, Lamendola C, McLaughlin T, Reaven GM, Tsao PS. Effect of rosiglitazone treatment on circulating vascular and inflammatory markers in insulin-resistant subjects. Diab Vasc Dis Res. 2005;2(1):37-41.

64. Vogel S, Thein SL. Platelets at the crossroads of thrombosis, inflammation and haemolysis. Br J Haematol. 2018;180(5): 761-7.

65. Blair HA. Crizanlizumab: First Approval. Drugs. 2020;80(1): 79-84.

66. Andoh A, Tsujikawa T, Hata K, Araki Y, Kitoh K, Sasaki M, et al. Elevated circulating platelet-derived microparticles in patients with active inflammatory bowel disease. Am J Gastroenterol. 2005;100(9):2042-8.

67. Wang F, Wang NS, Yan CG, Li JH, Tang LQ. The significance of platelet activation in rheumatoid arthritis. Clin Rheumatol. 2007;26(5):768-71.

68. Russwurm S, Vickers J, Meier-Hellmann A, Spangenberg P, Bredle D, Reinhart K, et al. Platelet and leukocyte activation correlate with the severity of septic organ dysfunction. Shock. 2002;17(4):263-8.

69. Shimizu M, Konishi A, Nomura S. Examination of biomarker expressions in sepsis-related DIC patients. Int J Gen Med. 2018;11:353-61.

70. Herter JM, Rossaint J, Spieker T, Zarbock A. Adhesion molecules involved in neutrophil recruitment during sepsisinduced acute kidney injury. J Innate Immun. 2014;6(5):597-606.

71. Liverani E, Rico MC, Tsygankov AY, Kilpatrick LE, Kunapuli SP. P2Y12 Receptor Modulates Sepsis-Induced Inflammation. Arterioscler Thromb Vasc Biol. 2016;36(5):961-71.

72. Erbel C, Korosoglou G, Ler P, Akhavanpoor M, Domschke G, Linden F, et al. CXCL4 Plasma Levels Are Not Associated with the Extent of Coronary Artery Disease or with Coronary Plaque Morphology. PLoS One. 2015;10(11):e0141693.

73. Piorkowski M, Fischer S, Stellbaum C, Jaster M, Martus P, Morguet AJ, et al. Treatment with ezetimibe plus low-dose atorvastatin compared with higher-dose atorvastatin alone: is sufficient cholesterol-lowering enough to inhibit platelets?. J Am Coll Cardiol. 2007;49(10):1035-42.

74. Heitzer T, Rudolph V, Schwedhelm E, Karstens M, Sydow K, Ortak M, et al. Clopidogrel improves systemic endothelial nitric oxide bioavailability in patients with coronary artery disease: evidence for antioxidant and antiinflammatory effects. Arterioscler Thromb Vasc Biol. 2006;26(7):1648-52.

75. Braunersreuther V, Steffens S, Arnaud C, Pelli G, Burger F, Proudfoot A, et al. A novel RANTES antagonist prevents progression of established atherosclerotic lesions in mice. Arterioscler Thromb Vasc Biol. 2008;28(6):1090-6.

76. Vrij AA, Rijken J, Van Wersch JW, Stockbrugger RW. Platelet factor 4 and beta-thromboglobulin in inflammatory bowel disease and giant cell arteritis. Eur J Clin Invest. 2000;30(3): $188-94$.

77. Fagerstam JP, Whiss PA, Strom M, Andersson RG. Expression of platelet P-selectin and detection of soluble P-selectin, NPY and RANTES in patients with inflammatory bowel disease. Inflamm Res. 2000;49(9):466-72.

78. Yeo L, Adlard N, Biehl M, Juarez M, Smallie T, Snow M, et al. Expression of chemokines CXCL4 and CXCL7 by synovial macrophages defines an early stage of rheumatoid arthritis. Ann Rheum Dis. 2016;75(4):763-71.

79. Torikai E, Kageyama Y, Suzuki M, Ichikawa T, Nagano A. The effect of infliximab on chemokines in patients with rheumatoid arthritis. Clin Rheumatol. 2007;26(7):1088-93.
80. Klimiuk PA, Sierakowski S, Domyslawska I, Chwiecko J. Serum chemokines in patients with rheumatoid arthritis treated with etanercept. Rheumatol Int. 2011;31(4):457-61.

81. Klimiuk PA, Kita J, Chwiecko J, Sierakowski S. The changes in serum chemokines following leflunomide therapy in patients with rheumatoid arthritis. Clin Rheumatol. 2009;28(1):17-21.

82. Boiardi L, Macchioni P, Meliconi R, Pulsatelli L, Facchini A, Salvarani C. Relationship between serum RANTES levels and radiological progression in rheumatoid arthritis patients treated with methotrexate. Clin Exp Rheumatol. 1999;17(4):419-25.

83. Klimiuk PA, Sierakowski S, Domyslawska I, Chwiecko J. Regulation of serum chemokines following infliximab therapy in patients with rheumatoid arthritis. Clin Exp Rheumatol. 2006; 24(5):529-33.

84. Grommes J, Alard JE, Drechsler M, Wantha S, Morgelin M, Kuebler WM, et al. Disruption of platelet-derived chemokine heteromers prevents neutrophil extravasation in acute lung injury. Am J Respir Crit Care Med. 2012;185(6):628-36.

85. Bigalke B, Geisler T, Stellos K, Langer H, Daub K, Kremmer E, et al. Platelet collagen receptor glycoprotein VI as a possible novel indicator for the acute coronary syndrome. Am Heart J. 2008;156(1):193-200.

86. Bigalke B, Stellos K, Geisler T, Kremmer E, Seizer P, May AE, et al. Expression of platelet glycoprotein VI is associated with transient ischemic attack and stroke. Eur J Neurol. 2010;17(1): 111-7.

87. Al-Tamimi M, Gardiner EE, Thom JY, Shen Y, Cooper MN, Hankey GJ, et al. Soluble glycoprotein VI is raised in the plasma of patients with acute ischemic stroke. Stroke. 2011;42(2):498500 .

88. Moraes LA, Spyridon M, Kaiser WJ, Jones CI, Sage T, Atherton $\mathrm{RE}$, et al. Non-genomic effects of PPARgamma ligands: inhibition of GPVI-stimulated platelet activation. J Thromb Haemost. 2010;8(3):577-87.

89. Jiang P, Loyau S, Tchitchinadze M, Ropers J, Jondeau G, Jandrot-Perrus M. Inhibition of Glycoprotein VI Clustering by Collagen as a Mechanism of Inhibiting Collagen-Induced Platelet Responses: The Example of Losartan. PLoS One. 2015; 10(6): 0128744.

90. Voors-Pette C, Lebozec K, Dogterom P, Jullien L, Billiald P, Ferlan P, et al. Safety and Tolerability, Pharmacokinetics, and Pharmacodynamics of ACT017, an Antiplatelet GPVI (Glycoprotein VI) Fab. Arterioscler Thromb Vasc Biol. 2019;39(5):95664.

91. Jadoui S, Le Chapelain O, Ollivier V, Mostefa-Kara A, Di Meglio L, Dupont S, et al. Glenzocimab does not impact glycoprotein VI-dependent inflammatory haemostasis. Haematologica. 2021;106(7):2000-3.

92. Barrachina MN, Hermida-Nogueira L, Moran LA, Casas V, Hicks SM, Sueiro AM, et al. Phosphoproteomic Analysis of Platelets in Severe Obesity Uncovers Platelet Reactivity and Signaling Pathways Alterations. Arterioscler Thromb Vasc Biol. 2021;41(1):478-90.

93. Fei M, Xiang L, Chai X, Jin J, You T, Zhao Y, et al. Plasma soluble C-type lectin-like receptor-2 is associated with the risk of coronary artery disease. Front Med. 2020;14(1):81-90.

94. Payne H, Ponomaryov T, Watson SP, Brill A. Mice with a deficiency in CLEC-2 are protected against deep vein thrombosis. Blood. 2017;129(14):2013-20.

95. Tsukiji N, Osada M, Sasaki T, Shirai T, Satoh K, Inoue O, et al. Cobalt hematoporphyrin inhibits CLEC-2-podoplanin interaction, tumor metastasis, and arterial/venous thrombosis in mice. Blood Adv. 2018;2(17):2214-25.

96. Kim C, Kim T, Yoo J, Sheen DH, Lee SK, Choi EH, et al. Longterm Treatment with Anti-platelet Agents for Collagen-induced Arthritis Improves Radiological Findings. Osong Public Health Res Perspect. 2017;8(3):179-84.

97. Montague SJ, Delierneux C, Lecut C, Layios N, Dinsdale RJ, Lee $\mathrm{CS}$, et al. Soluble GPVI is elevated in injured patients: shedding 
is mediated by fibrin activation of GPVI. Blood Adv. 2018;2(3):240-51.

98. Rayes J, Watson SP, Nieswandt B. Functional significance of the platelet immune receptors GPVI and CLEC-2. J Clin Invest. 2019;129(1):12-23. 